\title{
Caracterização de Diaporthe citri em Diferentes Meios de Cultura, Condições de Temperatura e Luminosidade*
}

\author{
Márcia de H. Nozaki**, Margarete Camargo \& Modesto Barreto \\ Laboratório de Fitopatologia, Departamento de Fitossanidade, Universidade Estadual Paulista, Faculdade de Ciências \\ Agrárias e Veterinárias, Campus de Jaboticabal, CEP 14884-900, Jaboticabal, SP, e-mail: manozaki@ fcav.unesp.br
}

(Aceito para publicação em 02/02/2004)

Autor para correspondência: Márcia de H. Nozaki

NOZAKI, M.H., CAMARGO, M. \& BARRETO, M. Caracterização de Diaporthe citri em meios de cultura e diferentes condições de temperatura e luminosidade. Fitopatologia Brasileira 29:429-432. 2004.

\section{RESUMO}

Estudou-se o crescimento micelial de dez isolados de Diaporthe citri, utilizando-se seis meios de cultura (aveia-ágar, maltose-peptona-ágar, batata-dextrose-ágar, folha de laranja-dextroseágar, folha de limão-dextrose-ágar, milho-ágar) à temperatura de 22 $\pm 2{ }^{\circ} \mathrm{C}$ e fotoperíodo de $12 \mathrm{~h}$ claro/ $12 \mathrm{~h}$ escuro. $\mathrm{O}$ cultivo em meio de batata-dextrose-ágar (BDA) foi conduzido em cinco temperaturas diferentes $\left(10,15,20,25\right.$ e $\left.30^{\circ} \mathrm{C}\right)$. Três diferentes regimes de luminosidade ( $12 \mathrm{~h}$ claro/12 h escuro, claro contínuo, escuro contínuo) foram utilizados para verificar o crescimento do fungo. Foram observadas variações na produção de picnídios e de massa micelial nos diferentes meios de cultura, temperaturas e regimes de luminosidade testados, sendo que, para a maioria dos isolados, o meio de cultura de aveia-ágar, a faixa de 20 a $25{ }^{\circ} \mathrm{C}$ e o regime de claro contínuo induziram maior crescimento micelial. A produção de picnídios foi maior para o regime de luz contínua. O teste de patogenicidade foi feito por inoculação de discos de micélio de 5 mm de diâmetro em ferimentos em ramos e caule de limão 'Feminelo' (Citrus limon) enxertado em citrumelo 'Swingle'(Poncirus trifoliolata x Citrus paradisi) e plantas de limão 'Cravo' ( $C$. limonia) enxertados com laranja 'Valência' ( $C$. sinensis). Após sete dias, houve o aparecimento de exsudação de goma nas plantas inoculadas com os isolados, mas não na testemunha. Todos os isolados mostraram-se patogênicos, sendo os isolados PC2 e PC5, os que causaram comprimento de lesão maior nas plantas.

Palavras-chave adicionais: citros, melanose, crescimento micelial, produção de picnídios.

\section{ABSTRACT}

Characterization of Diaporthe citri under different culture media, temperature and luminosity conditions

The mycelial growth of ten Diaporthe citri isolates was studied comparing six culture media (oatmeal-agar, malt-peptoneagar, potato-dextrose-agar, orange leaf-dextrose-agar, lemon leafdextrose-agar, corn-agar) under $22 \pm 2{ }^{\circ} \mathrm{C}$ and $12 \mathrm{~h} \mathrm{light} / 12 \mathrm{~h}$ dark. The evaluation of the mycelial growth of the fungi was also compared under five different temperatures $\left(10,15,20,25\right.$ and $\left.30^{\circ} \mathrm{C}\right)$ and three different luminosity conditions ( $12 \mathrm{~h}$ light/12 h dark, continuous light and continuous dark) on potato-dextrose-agar media (PDA).
Variations in pycnidial and mycelial mass production were observed in the different media, temperature and luminosity conditions tested. For most isolates, oatmeal-agar, $20-25{ }^{\circ} \mathrm{C}$ and continuous light promoted best sporulation. The pycnidial production was greater under continuous light. The pathogenicity test was made by inoculating mycelial discs of $5 \mathrm{~mm}$ on sores made in twigs and stem of citrus (Citrus spp.) cultivars. After seven days, gum exudation was observed in plants that were inoculated with the isolates, but not on control. All isolates were pathogenic, but PC2 and PC5 caused bigger lesions in plants.
A melanose é uma doença de citros (Citrus spp.) causada pelo fungo Diaporthe citri (Wolf.), cuja fase anamorfa corresponde a Phomopsis citri Fawcet. Todas as espécies de citros são suscetíveis ao fungo, sendo que, pomelos (Citrus paradisi Macf) e limões (Citrus limon Burmann) tendem a ser mais afetados que outras (Whiteside et al., 1993; Bushong \& Timmer, 2000; Timmer, 2000).

A incidência, assim como a severidade, vem aumentando ano a ano no país, sendo que a ocorrência da doença é maior em pomares velhos e mal conduzidos. Os sintomas aparecem uma semana após a infecção em forma de pequenos pontos unidos, pardos e discretos ou confluentes. As folhas são

\footnotetext{
*Parte da dissertação de Mestrado do primeiro autor. Universidade Estadual Paulista, Faculdade de Ciências Agrárias e Veterinárias. (2003) **Bolsista CAPES
}

suscetíveis quando estão em crescimento, tornando-se resistentes após atingirem seu tamanho final. Os frutos são suscetíveis quando jovens, tornando-se resistentes com cerca de 12 semanas de idade, a contar da data de queda das pétalas. Em folhas e ramos novos, os sintomas iniciam-se na forma de pequenas anasarcas, de menos de $1 \mathrm{~mm}$ de diâmetro, deprimidas no centro com um halo amarelado ao seu redor, que com o tempo desaparece. Com o rompimento da cutícula, uma substância gomosa é exsudada na região afetada, que depois adquire uma consistência firme e de coloração marrom, fazendo com que as lesões se tornem salientes e ásperas ao tato. Essas manchas nada mais são do que as secreções dos tecidos afetados em reação à ação do fungo, que fica assim impedido de se desenvolver (Feichtenberger et al., 1997).

$\mathrm{Na}$ fase anamórfica, o fungo forma picnídios globosos 
em ramos secos. Os picnídios são negros, cônicos ou lenticulares e apresentam ostíolos. Há dois tipos de conídios presentes: conídios alfa que são hialinos, unicelulares, fusiformes a elipsoidais e bigutulados e conídios beta, hialinos unicelulares, filiformes, curvados e freqüentemente na forma de gancho. Os picnidiósporos são produzidos em grande número no interior de picnídios formando massas filamentosas denominadas cirros (Punithalingam \& Holliday, 1973; Feichtenberger et al., 1997). Os conídios são disseminados pela água de chuva a curtas distâncias e esses propágulos são levados aos frutos, folhas ou galhos verdes (Kuhara, 1999; Rossetti, 2001).

Para determinar o tempo e condições necessárias para a produção de picnídios, Ibanez \& Timmer (1999) deixaram à exposição em campo durante oito meses, pomelos apresentando sintomas de melanose. A temperatura e a produção de picnídios foram avaliadas mensalmente. Ao final, estes observaram que médias de temperatura entre $15 \mathrm{a} 25^{\circ} \mathrm{C}$ e precipitações em torno de $350 \mathrm{~mm}$ aumentaram substancialmente a produção de picnídios.

Para a reprodução de fungos in vitro, fatores favoráveis são requeridos, tanto nutricionais quanto ambientais. Dentre os fatores ambientais, estão temperatura e luminosidade, importantes para o crescimento micelial e produção de esporos. Porém, nem sempre as condições que favorecem o crescimento são as mesmas para esporulação. A luz exerce efeito direto sobre o fungo, induzindo ou inibindo a formação de estruturas reprodutivas. Sabe-se ainda que, alguns meios de cultura são mais favoráveis para a esporulação de fungos que outros, por apresentarem carboidratos complexos que são menos adequados para a produção de hifas vegetativas, porém mais adequados à produção de esporos.

A influência do regime luminoso sobre o crescimento micelial foi observada para isolados de Phomopsis anacardii Early \& Punithalingam e $P$. mangiferae Ahmad por Gurgel et al. (2002).

O presente trabalho teve como objetivo caracterizar diferentes isolados de $D$. citri obtidos de plantas cítricas, quanto à patogenicidade e desenvolvimento, em diferentes meios de cultura, e sob diferentes condições de temperatura e luminosidade.

O trabalho foi desenvolvido no Laboratório de Fitopatologia e casa de vegetação do Departamento de Fitossanidade da FCAV/UNESP - Jaboticabal, SP.

Os isolados utilizados foram obtidos de lesões em folhas (PC3, PC7, PC10), ramos (PC1, PC2, PC4, PC5, PC9) e frutos (PC6, PC11) de plantas cítricas com sintomas característicos de melanose, das regiões de Conchal, Monte Alto e Jaboticabal/ SP. Foi utilizado o meio de batata-dextrose-ágar (BDA) para isolamento e manutenção das colônias do fungo.

No primeiro ensaio, os isolados foram submetidos a diferentes regimes de temperaturas, sendo estas: 10, 15, 20, 25 e $30^{\circ} \mathrm{C}$. Foi utilizado meio BDA para o desenvolvimento dos isolados sendo colocado disco micelial de $5 \mathrm{~mm}$, obtidos de culturas previamente desenvolvidos em BDA com 15 dias de idade. Após a repicagem, procedeu-se à incubação em câmaras de crescimento com os diferentes regimes de temperatura, sob conjunto de lâmpadas fluorescentes e regime de alternância luminosa ( $12 \mathrm{~h}$ claro/12 h escuro). Cada tratamento foi feito com cinco repetições.

$\mathrm{O}$ crescimento micelial foi observado e medido diariamente até que o crescimento de um dos isolados, em algum dos tratamentos, atingisse completamente as bordas da placa de Petri.

$\mathrm{O}$ delineamento experimental foi inteiramente casualizado, seguindo-se o esquema fatorial 10 x 5 com cinco repetições.

Para a verificação da influência de diferentes meios de cultura sobre o crescimento e formação de estruturas reprodutivas de $D$. citri, foram utilizados seis diferentes meios de cultura, sendo estes, com as respectivas composições para cada litro de meio: BDA: $200 \mathrm{~g}$ de batata, $20 \mathrm{~g}$ de dextrose, 20 $\mathrm{g}$ de ágar; aveia-ágar (AA: $60 \mathrm{~g}$ de aveia em flocos, $18 \mathrm{~g}$ de ágar e $0,5 \mathrm{~g}$ de extrato de levedura); maltose-peptona-ágar (MPA: $4 \mathrm{~g}$ de maltose, $1 \mathrm{~g}$ de peptona, $18 \mathrm{~g}$ de ágar); milho (MM: $200 \mathrm{~g}$ de grãos de milho, $18 \mathrm{~g}$ de ágar); folha de laranja (FLa: $200 \mathrm{~g}$ de folha de laranjeira, $20 \mathrm{~g}$ de dextrose e $18 \mathrm{~g}$ de ágar); folha de limoeiro (FLi: $200 \mathrm{~g}$ de folha de limoeiro, $20 \mathrm{~g}$ de dextrose e $18 \mathrm{~g}$ de ágar).

O ensaio foi instalado utilizando fragmentos de micélio de $5 \mathrm{~mm}$ de diâmetro das colônias dos fungos desenvolvidos em BDA durante 15 dias.

Foram testados cinco isolados do fungo (PC1, PC2, PC3, PC4, PC5) e, com base em resultados anteriores, os fungos foram incubados em temperatura média de $22 \pm 2^{\circ} \mathrm{C}$.

A avaliação do crescimento micelial foi realizada como no ensaio anterior. Após 30 dias, foi realizada a avaliação das estruturas reprodutivas formadas pelos fungos, através da quantidade de picnídios produzidos. Os conídios foram avaliados com auxílio de lâminas feitas pelo esmagamento dos picnídios e observados ao microscópio ótico no aumento de 40 vezes. O número de picnídios foi avaliado visualmente com auxílio de microscópio estereoscópio.

O delineamento experimental foi inteiramente casualizado, seguindo-se o esquema fatorial 5 × 6 com cinco repetições.

Objetivando estimar a influência de diferentes regimes de luminosidade sobre o crescimento de $D$. citri, dez isolados (PC1, PC2, PC3, PC4, PC5, PC6, PC7, PC9, PC10, PC11) foram previamente cultivados em meio $\mathrm{BDA}$ por um período de 15 dias, dos quais discos miceliais de $5 \mathrm{~mm}$ de diâmetro foram retirados dos bordos das colônias e repicados em placas de Petri contendo meio AA. Após repicagem, os fungos foram incubados nas seguintes condições: exposição contínua à luz, exposição a períodos alternados de $12 \mathrm{~h}$ de luz e $12 \mathrm{~h}$ de escuro e, escuro contínuo. A incubação foi realizada em câmara de crescimento com temperatura de $22 \pm 2^{\circ} \mathrm{C}$.

As avaliações de crescimento micelial e formação de picnídios foram realizadas aos sete, 14, 21 e 30 dias após repicagem.

O delineamento experimental foi inteiramente casualizado, seguindo-se o esquema fatorial $10 \times 3$ com cinco repetições.

Os testes de patogenicidade foram realizados em plantas de limão 'Feminelo' enxertadas com citrumelo 'Swingle' com 
Caracterização de Diaporthe citri em meios de cultura e diferentes ...

aproximadamente 110 dias de idade que foram mantidas em vasos de 101 de solo. O primeiro ensaio foi realizado com cinco isolados (PC1, PC2, PC3, PC4, PC5) e a testemunha. O segundo ensaio foi realizado com os outros cinco isolados restantes (PC6, PC7, PC9, PC10, PC11).

Foi realizado, ainda, um terceiro ensaio, utilizando os isolados PC1, PC2, PC3, PC4 e PC5 na inoculação de plantas de limão 'Cravo' enxertadas com laranja 'Valência'.

A inoculação foi realizada através da inserção em ramos e caule de discos miceliais do fungo com $5 \mathrm{~mm}$ de diâmetro cultivados em BDA. Realizaram-se ferimentos em forma de "T" invertido no tronco e ramos das plantas inserindo o disco micelial no tecido e protegendo com fita plástica por sete dias. Para a testemunha foram utilizados discos de BDA realizando o mesmo procedimento de inoculação descrito.

As avaliações foram realizadas aos 14 dias após a inoculação, examinando-se a presença de goma e medindo-se o comprimento das lesões. $\mathrm{O}$ delineamento experimental foi inteiramente casualizado, com cinco repetições para cada tratamento.

As características culturais e morfológicas apresentadas pelos isolados de $D$. citri corresponderam às descrições relatadas por Punithalingam \& Holliday (1973).

Nas diferentes temperaturas às quais foram submetidos, a maioria dos isolados tiveram o crescimento favorecido entre 20 e $25^{\circ} \mathrm{C}$. Sendo que, a $25^{\circ} \mathrm{C}$, após sete dias de incubação, apresentaram crescimento de $4-7,5 \mathrm{~mm} / \mathrm{dia}$. Na temperatura de $10{ }^{\circ} \mathrm{C}$ os isolados não apresentaram crescimento significativo, enquanto a $15^{\circ} \mathrm{C}$ os isolados PC9, PC10 e PC11 obtiveram os melhores crescimentos, diferindo estatisticamente dos demais. $\mathrm{O}$ isolado PC10 foi o que apresentou maior crescimento micelial diferindo estatisticamente dos demais na temperatura de $20^{\circ} \mathrm{C}$.

O meio de AA proporcionou maior crescimento micelial, além de maior produção de picnídios para todos os isolados, exceto para PC2 que não produziu estas estruturas em nenhum dos meios testados.

A inclusão de material vegetal no meio de cultura é uma técnica usada para estimular a produção de esporos para alguns fungos. Segundo Almeida (1982), porém, o meio de haste de soja não diferiu do meio de aveia na produção de picnídios de Phomopsis sojae Lehman. No presente ensaio foi verificado que tanto a inclusão de folha de laranja como de limão no meio de cultura não estimularam a produção de picnídios.

O regime de luminosidade contínuo foi favorável tanto para o maior crescimento micelial quanto para a maior produção de picnídios para todos os isolados, em menor período de tempo. Aos sete dias após transferência, em presença de luz contínua, a maioria dos isolados apresentou maior crescimento micelial em relação aos demais regimes de luz, com exceção do isolado PC2 cujo crescimento micelial foi igual na luz e no escuro contínuo e PC5 para o qual o crescimento micelial foi semelhante estatisticamente em luz contínua e alternada.

Resultados semelhantes foram obtidos por Coelho et al. (1997) estudando a formação de picnídios e conídios de isolados de Phomopsis spp. e Phoma spp., provenientes de sementes de ipê amarelo (Tabepuia serratifolia Vahl. Nichols) e jacarandá da Bahia (Dalberghia nigra Vell. Fr. All.), em diferentes meios de cultura, temperaturas e padrões de luminosidade. Neste, observaram variações na produção de picnídios e conídios, sendo para a maioria dos isolados o meio AA e regime de claro contínuo, as condições que induziram maior esporulação.

Através da análise dos dados obtidos, verifica-se que condições mais adequadas para o desenvolvimento e reprodução do fungo testado foram temperaturas na faixa de 20 e $25{ }^{\circ} \mathrm{C}$, meio AA e regime de luz contínua.

Nos testes de patogenicidade realizados, as plantas inoculadas apresentaram sintomas característicos, como a exsudação da goma e morte dos tecidos lesionados, sendo confirmada a presença de estruturas do fungo em microscópio estereoscópio e ótico.

No primeiro ensaio verificou-se que as médias obtidas das lesões provocadas pelos isolados PC2, PC4 e PC5 não diferiram estatisticamente entre si. Os dados obtidos no segundo ensaio mostram que os cinco isolados testados não diferiram entre si quanto a média do tamanho da lesão provocado.

Os resultados obtidos da inoculação em laranja 'Valência' mostram que não houve diferença significativa entre isolados, mas todos diferiram da testemunha (Tabela 1).

TABELA 1 - Comprimento das lesões $(\mathrm{cm})$ em plantas cítricas inoculadas com isolados de Diaporthe citri, aos 14 dias após inoculação

\begin{tabular}{|c|c|c|c|c|c|}
\hline Isolado & $1^{\circ}$ Ensaio $^{1}$ & Isolado & $2^{0}$ ensaio $^{1}$ & Isolado & $3^{\circ}$ ensaio \\
\hline PC1 & $3,27 b^{3}$ & PC6 & $2,12 a^{3}$ & PC1 & $2,05 \mathrm{a}^{3}$ \\
\hline $\mathrm{PC2}$ & $5,08 \mathrm{a}$ & PC7 & $1,75 \mathrm{a}$ & PC2 & $2,55 \mathrm{a}$ \\
\hline PC3 & $3,33 \mathrm{~b}$ & PC9 & $1,56 \mathrm{a}$ & PC3 & $2,30 \mathrm{a}$ \\
\hline PC4 & $4,25 \mathrm{ab}$ & PC10 & $1,43 \mathrm{a}$ & PC4 & $2,45 \mathrm{a}$ \\
\hline PC5 & $3,83 \mathrm{ab}$ & PC11 & $1,75 \mathrm{a}$ & PC5 & $2,15 \mathrm{a}$ \\
\hline Test. & $0,00 \mathrm{c}$ & Test. & - & Test. & $0,00 \mathrm{~b}$ \\
\hline $\begin{array}{l}\text { Teste F = } \\
\text { C.V. }(\%)=\end{array}$ & $\begin{aligned} & 0,29^{\text {N.S. } 4} \\
= & 33,23\end{aligned}$ & $\begin{array}{l}\text { Teste F = } \\
\text { C.V. }(\%)\end{array}$ & $\begin{aligned} & 2,07^{\mathrm{N} . \mathrm{S}} \\
= & 44,59\end{aligned}$ & \multicolumn{2}{|c|}{$\begin{array}{l}\text { Teste } \mathbf{F}=0,83^{\text {N.S. }} \\
\text { C.V. }(\%)=29,45\end{array}$} \\
\hline DMS = & 1,60 & DMS = & 1,11 & DMS = & 0,75 \\
\hline
\end{tabular}

${ }^{1} 1^{\circ}$ e $2^{\circ}$ ensaio: teste de patogenicidade em plantas de Feminelo x Citrumelo 'Swingle';

${ }^{2} 3^{\circ}$ ensaio: teste de patogenicidade em plantas de Limão 'Cravo' x Laranja 'Valência';

${ }^{3}$ Médias seguidas por letras distintas na vertical diferem entre si pelo teste de Tukey a 5\% de probabilidade.

${ }^{4} \mathrm{~N} . \mathrm{S}$. = Não significativo;

\section{REFERÊNCIAS BIBLIOGRÁFICAS}

ALMEIDA, A.M.R. Efeito de luz e meios de cultura sobre crescimento micelial, formação e tamanho de picnídios e esporulação de isolados de Phomopsis sojae Leh. In: Seminário Nacional de Pesquisa de Soja. Brasília, 2, 1981. Londrina. Anais... Brasília: Embrapa/SNI, 1982. pp.216-226.

BUSHONG, P.M. \& TIMMER, L.W. Evaluation of postinfection control of citrus scab and melanose with benomyl, fenbuconazole and azoxystrobin. Plant Disease 84:1246-1249. 2000.

COElHO, R.M.S., CASTRO, H.A. de. \& MENEZES, M. 
M.H. Nozaki et al.

Esporulação de Phomopsis e Phoma em diferentes meios de cultura e condições de temperatura e luminosidade. Summa Phytopathologica 23:176-180. 1997.

FEICHTENBERGER, E., MÜLlER, G. W. \& GUIRADO, N. Doenças do citros. In: Kimati, H., Amorim, L., Bergamin Filho, A., Camargo, L.E.A. \& Rezende, J.A.M. (Eds.). Manual de fitopatologia: doenças das plantas cultivadas. 3. ed. São Paulo: Agronômica Ceres, 1997.v.2. pp.261-296.

GURGEL, L.M.S., MENEZES, M. \& COELHO, R.S.B. Estudo comparativo de isolados de Phomopsis anacardii e Phomopsis mangiferae através da patogenicidade e nutrição de $\mathrm{C}$ e $\mathrm{N}$, em três regimes de luminosidade. Summa Phytopathologica 28:160-166. 2002.

IBANEZ, A.M. \& TIMMER, L.W. Effect of weather factors on pycnidium production and occurrence of citrus melanose in the field. Phytopathology 89:S35. 1999.
KUHARA, S. The application of the epidemiologic simulation model "MELAN" to control citrus melanose caused by Diaporthe citri (Faw.) Wolf. Food and Fertilizer Technology Center Extension Bulletins, National Fruit Research Institute, Japan, 1999, 8p.

PUNITHALINGAM, E. \& HOLLIDAY, P. Diaporthe citri (conidial state: Phomopsis citri). CMI Descriptions of Pathogenic Fungi and bacteria. Commonwealth Mycological Institute, n. 396, 1973.

ROSSETTI, V.V. Manual ilustrado de doenças de citros. Piracicaba: Fealq/Fundecitrus, 2001.

TIMMER, L.W. 2000 Florida Citrus Pest Management Guide: Melanose. Fact Sheet PP-145. Florida Cooperative Extension Service, Institute of Food and Agricultural Sciences, University of Florida, 2000 .

WHITESIDE, J.O., GARNSEY, S.M. \& TIMMER, L.W. Compendium of Citrus Diseases. The American Phytopathological Society, 2 ed., 1993. 